\title{
Author Correction: Gut microbiome pattern reflects healthy ageing and predicts survival in humans
}

Tomasz Wilmanski (D), Christian Diener, Noa Rappaport (1D), Sushmita Patwardhan, Jack Wiedrick, Jodi Lapidus, John C. Earls, Anat Zimmer, Gustavo Glusman (D), Max Robinson (1D, James T. Yurkovich (1), Deborah M. Kado, Jane A. Cauley, Joseph Zmuda, Nancy E. Lane, Andrew T. Magis (1D, Jennifer C. Lovejoy, Leroy Hood, Sean M. Gibbons (1), Eric S. Orwoll (iD and Nathan D. Price (D)

Correction to: Nature Metabolism https://doi.org/10.1038/s42255-021-00348-0, published online 18 February 2021.

In the version of this article initially published, NIAMS grant R01AR061445 was not included in the Acknowledgements. The error has been corrected in the HTML and PDF versions of the article.

Published online: 18 March 2021

https://doi.org/10.1038/s42255-021-00377-9

(c) The Author(s), under exclusive licence to Springer Nature Limited 2021 